\title{
Low Back Pain in Pregnancy
}

\author{
${ }^{1}$ Vikram Khanna, ${ }^{2}$ Ranjana Khanna, ${ }^{3}$ Parul Gupta
}

\begin{abstract}
Low back pain in pregnancy is a common complaint. Psychologically, it has a negative effect on the patient, adversely affecting the quality of life.

Presenting either as pelvic girdle or as lumbar pain, accurate and early diagnosis is essential for adequate management of patients with low back pain in pregnancy. The mainstay of management is conservative. There is no established protocol and the treatment has to be tailored for each patient.
\end{abstract}

Keywords: Low back pain, Lumbar pain, Pelvic girdle pain, Pregnancy.

How to cite this article: Khanna V, Khanna R, Gupta P. Low Back Pain in Pregnancy. Int J Recent Surg Med Sci 2016;2(1):23-27.

Source of support: Nil

Conflict of interest: None

\section{INTRODUCTION}

Pregnant women often experience low back pain (LBP), which not only has a negative impact on their psychology but may also interfere with their activities of daily living. Hippocrates, Vesalius, Pinean, Hunter, and many others were the first to describe this condition of low backache in pregnancy. Walde and Ostgaard worked in this direction and differentiated pelvic girdle pain from lumbar pain. ${ }^{1}$ About $50 \%$ of all pregnant females suffer from LBP. $^{2-4}$ The etiology may be mechanical, hormonal, or others. ${ }^{2,3,5-12}$

Low back pain in pregnancy may be classified into two types: Pelvic girdle pain (PGP) and lumbar pain (LP). Sometimes, a combination of the two may be the cause of low backache in pregnancy. Pelvic girdle pain is the more common of the two and consists of deep stabbing continuous or recurrent pain, which maybe unilateral or bilateral. It is generally present between the posterior iliac crest and the gluteal fold, which radiates toward the posterolateral thigh and knee but not the foot. ${ }^{13}$ This type of pain is severe during pregnancy as compared to the postpartum period and it causes a deep negative impact

\footnotetext{
${ }^{1,3}$ Consultant, ${ }^{2}$ Senior Consultant

${ }^{1}$ Department of Orthopaedics, Ranjana Hospital, Allahabad Uttar Pradesh, India

2,3 Department of Obstetrics and Gynecology, Ranjana Hospital Allahabad, Uttar Pradesh, India
}

Corresponding Author: Vikram Khanna, Consultant, Department of Orthopaedics, Ranjana Hospital, Allahabad, Uttar Pradesh India, Phone: +917073647974, e-mail: 86.khanna@gmail.com on the psychology of the patient. ${ }^{14}$ It can be differentiated from other causes by the posterior pain provocation test (PPPT) ${ }_{1}^{15}$ which is positive in case of PGP. ${ }^{2,3,6,16,17}$

Lumbar pain is the same as experienced by nonpregnant females. The pain is present over the lumbar region with tenderness over the paraspinal muscle..$^{13}$ This pain is posture dependent and is seen more commonly in the postpartum period. ${ }^{14}$ The PPPT is negative in such cases.

Lumbar pain and PGP should be diagnosed early and managed accordingly. This can be done with a detailed history and good clinical examination. ${ }^{18}$ Motion palpation test may also be used for the diagnosis of the same. ${ }^{19}$

Management of the low back ache in pregnancy has to be tailored according to the specific complaints of the patients. Conservative therapy is found to be the gold standard for the treatment of the same. This includes physiotherapy, stabilization belts, nerve stimulation, pharmacological treatment, acupuncture, massage, relaxation, and yoga. ${ }^{2,3,8,20,21}$ In general, low back ache in pregnancy constitutes a benign prognosis with a relatively simple treatment, provided early diagnosis has been made.

The aim of this review article is to draw upon a consensus on the current practices of the management of the low back ache in pregnancy.

\section{PREVALENCE}

Incidence of low back ache varies from 20 to $90 \%$. Studies show incidence to be $50 \%$ of all the pregnancies. Majority of women are affected in their first pregnancy. ${ }^{22}$ In $8 \%$, activities of daily routine are affected and in $10 \%$ of patients the patient is unable to return to work because of $\mathrm{LBP}^{23}$

Low back pain is generally seen between the 20th and the 28th week. In a study done in the Netherlands, it was seen that the incidence of LBP was found to be $38 \%$ at 3 months postpartum and $13.8 \%$ at 12 months postpartum respectively.

\section{ETIOLOGY}

Many theories have been postulated, but a confirmed etiology remains at large.

One is the weight gaining hypothesis, which is based on the theory that with increase in body weight following pregnancy the belly increases in diameter and the center of gravity moves anterior to the spine and this increases the stress on the lower back, which causes LBP in pregnancy. $3,8,9,11$ This shift in center of gravity anteriorly has 
been associated with change in posture with increase in the lordosis and stress on the lower back. ${ }^{24}$ There may be some connection between LBP and the pelvic floor dysfunction (PFD), which can be diagnosed by a negative active SLR test and a positive PPPT test. ${ }^{13}$

Weight gain also causes an increase in the axial loading of the spine, causing the decrease in the intervertebral disk height along with increased vertebral body pressure. This may lead to compression of the spine and thus to prolonged pain. ${ }^{8}$

Abdominal muscle stretching due to the enlarging uterus causes muscle fatigue and maybe a contributing factor to LBP. ${ }^{3,8}$ According to a study, there may be some weak correlation between weak gluteal muscles and LBP during pregnancy. ${ }^{5}$

A significant number of patients develop pain in the first trimester of pregnancy, which may not be related to the mechanical factors, such as weight gain or size of the uterus. This pain may be caused due to hormonal changes that constitute the following changes. A tenfold rise in the hormone relaxin not only causes ligamentous laxity but may also be responsible for the generalized discomfort in the sacroiliac joint as well as in the lumbar region. However, there has not been any correlation of the serum relaxin levels and LBP. 2,3,6-10

Another theory explaining nocturnal pain states there is compression of the inferior vena cava by the expanding uterus, which leads to pelvic compression, and, hence, the pain. ${ }^{8}$ Sciatica is a rare presentation in pregnancy and if there is no evidence of disk degeneration then other rare causes of sciatica maybe considered. ${ }^{25}$ Osteitis condesans Ili may also be kept in mind in a case of refractory LBP in the postpartum period. ${ }^{26}$

\section{DIFFERENTIAL DIAGNOSIS}

Low back pain in pregnancy is seen commonly due to two conditions: PGP and LP. Pregnancy mobility index (PMI) is a questionnaire developed by Van de Pol to assess the ability of pregnant women to do their household activities. ${ }^{27}$ This along with Quebec back pain disability scale has been used to measure the disability due to LBP. ${ }^{8}$

Low back pain should be differentiated from pelvic instability pain. Pelvic instability is generally asymptomatic and resolves spontaneously and may appear as pelvic ring widening. ${ }^{28}$ Pelvic instability may develop due to forced expulsion or syphisiotomy, which is done for the management of obstructed labor and shoulder dystocia. $^{29-31}$

\section{RISK FACTORS}

There is much debate in the literature regarding the risk factors for LBP during pregnancy. The Owestry disability index (ODI) along with EuroQol and pain VAS score may assist in the early identification of the disease. ${ }^{8,32}$ The most common causes of LBP in pregnancy include pelvic trauma, LBP in previous delivery, and chronic LBP. $^{33,34}$ The number of previous pregnancies also plays an important role in LBP in pregnancy. ${ }^{35}$ However, it is nearly impossible to predict which of the pregnancies are going to land up with the LBP. It is easier to predict the LP type of LBP rather than the PGP. Low back pain during menstruation may be a risk factor for LBP during pregnancy. ${ }^{22}$ The LP type of LBP may be decreased with exercise, whereas PGP has no effect. ${ }^{2,3,32,36}$

Socioeconomic status has no role in LBP during pregnancy. ${ }^{37}$ A diagnosed case of hypermobility is a definite risk factor for LBP in pregnancy. ${ }^{38}$ Some studies have shown that the sex of the child maybe a cause of LBP in pregnancy. ${ }^{39}$ Certain dysplastic conditions may also prove to be a risk factor for the diagnosis of LBP in pregnancy. ${ }^{40}$ Obesity may also be a risk factor for the development of LBP in pregnancy. ${ }^{41}$ However, some studies have found that obesity is not a risk factor for the development of LBP. $^{2,4}$

Certain factors, such as spinal or epidural during pregnancy, high work load, contraceptive pills, and the age of the patient does not affect LBP in pregnancy. 2,3,22,42

\section{PREVENTION}

Pregnant females have to be educated on maintaining a good posture while doing their activities of daily routine along with an exercise regimen. ${ }^{43}$ This is helpful in LP type of pain and not helpful in preventing PGP type of LBP. $^{13}$ It is important for pregnant females to know how to lift weights during the entire period of pregnancy. The patients having PGP type of LBP are associated with muscle dysfunction. ${ }^{4}$

\section{Prognosis}

Low back pain generally increases with progression of the pregnancy. ${ }^{45}$ Although the pain decreases with progression of labor in the first trimester. Pain during the antenatal period may be an indicator of the amount of pain in the postpartum period. ${ }^{46}$

Pelvic girdle pain is more during antenatal period, whereas LP is more pronounced during postpartum period. Postpartum LBP is benign and is generally selflimiting with a good prognosis. ${ }^{2,8,17,47}$ The progression of LBP is not affected by cesarean section for childbirth. ${ }^{42}$

Depression adds to the postpartum LBP and should be taken into consideration while prescribing treatment for the same. ${ }^{48}$ Although, training and physiotherapy may or may not help in halting the progression of the pain. ${ }^{32,49}$ A tailor-made regime for patients may be useful. 
Table 1: Management of low back pain in pregnancy

\begin{tabular}{ll}
\hline Treatment of lumbar pain & Treatment of pelvic girdle pain \\
\hline Exercise - pacing, swimming & Decrease activities causing pain \\
Back support & Rest during acute attack \\
Use foot stool & Use pelvic belt \\
Midday rest & Activity modification \\
Avoid prolonged sitting & Support legs while lying down \\
\hline
\end{tabular}

Active Straight Leg Raise is the predictive test in pregnant females as the PPPT test is not very reliable..$^{50}$

\section{MANAGEMENT}

In the study, half of all women suffering from LBP sought medical help, whereas $70 \%$ of those seeking help received adequate treatment. ${ }^{51}$ Conservative management is preferred for LBP in pregnancy. A correct diagnosis as LP or PGP should be formed because the treatment varies. Treatment options include physiotherapy, stabilization belts, nerve stimulation, pharmacological treatment, acupuncture, massage, relaxation, and yoga. ${ }^{8}$ Basic management of LBP has been outlined in Table $1 .{ }^{21}$

Studies have shown that an intradermal injection of sterile water has shown to provide good pain relief, especially during labor. This provides good pain relief for upto 2 hours after administration, to the tune that it delays the requirement of epidural anesthesia. ${ }^{20}$

Auricular acupuncture has shown to give some relief to the pain. Though the results are not conclusive, but still it seems to be a promising method of treatment. ${ }^{52}$

The most common method of treatment of LBP has been found to be exercises. However, there has been no strong evidence on this method of treatment. There might be some effect on the cost of treatment on the final compliance of the patient also. ${ }^{7,16,49,53-56}$ Other methods of management include alteration of the activities of daily living, use of foot stools and back support, education regarding weight lifting techniques, taking midday rest, and massage. However, the efficacy remains unconfirmed. $3,8,10,57,58$

The management protocol is different while comparing LP and PGP. Acute attack of PGP calls for brief rest and lying in bed. Whereas management of LP constitutes the use of pillow, leg roll, back rest, etc., return to heavy activity has to be avoided and the use of sacral belt may help. In cases of persistent pain and disability, pharmacological agents for pain management may be used.

\section{CONCLUSION}

Low back pain during pregnancy is one of the most disabling features, which has a negative psychological impact on the patient. Although the treatment may not be curative, with early diagnosis and prompt management this can be very well controlled.

\section{REFERENCES}

1. Bastiaanssen JM, de Bie RA, Bastiaenen CH, Essed GG, van den Brandt PA. A historical perspective on pregnancyrelated low back and/or pelvic girdle pain. Eur J Obstet Gynecol Reprod Biol 2005 May 1;120(1):3-14.

2. Vleeming A, Albert HB, Ostgaard HC, Sturesson B, Stuge B. European guidelines for the diagnosis and treatment of pelvic girdle pain. Eur Spine J 2008 Jun;17(6):794-819.

3. Perkins J, Hammer RL, Loubert PV. Identification and management of pregnancy-related low back pain. J Nurse Midwifery 1998 Sep-Oct;43(5):331-340.

4. Sihvonen T, Huttunen M, Makkonen M, Airaksinen O. Functional changes in back muscle activity correlate with pain intensity and prediction of low back pain during pregnancy. Arch Phys Med Rehabil 1998 Oct;79(10):1210-1212.

5. Bewyer KJ, Bewyer DC, Messenger D, Kennedy CM. Pilot data: association between gluteus medius weakness and low back pain during pregnancy. Iowa Orthop J 2009;29:97-99.

6. van Dongen PW, de Boer M, Lemmens WA, Theron GB. Hypermobility and peripartum pelvic pain syndrome in pregnant South African women. Eur J Obstet Gynecol Reprod Biol 1999 May;84(1):77-82.

7. Stuge B, Hilde G, Vollestad N. Physical therapy for pregnancy related low back and pelvic pain: a systematic review. Acta Obstet Gynecol Scand 2003 Nov;82(11):983-990.

8. Sabino J, Grauer JN. Pregnancy and low back pain. Curr Rev Musculoskelet Med 2008 Jun;1(2):137-141.

9. To WW, Wong MW. Factors associated with back pain symptoms in pregnancy and the persistence of pain 2 years after pregnancy. Acta Obstet Gynecol Scand 2003 Dec;82(12): 1086-1091.

10. Wedenberg K, Moen B, Norling A. A prospective randomized study comparing acupuncture with physiotherapy for low-back and pelvic pain in pregnancy. Acta Obstet Gynecol Scand 2000 May;79(5):331-335.

11. Ostgaard HC, Andersson GB, Schultz AB, Miller JA. Influence of some biomechanical factors on low-back pain in pregnancy. Spine (Phila Pa 1976) 1993 Jan;18(1):61-65.

12. Pool-Goudzwaard AL, Slieker ten Hove MC, Vierhout ME, Mulder PH, Pool JJ, Snijders CJ, Stoeckart R. Relations between pregnancy-related low back pain, pelvic floor activity and pelvic floor dysfunction. Int Urogynecol J Pelvic Floor Dysfunct 2005 Nov-Dec;16(6):468-474.

13. Ostgaard HC, Zetherstrom G, Roos-Hansson E, Svanberg B. Reduction of back and posterior pelvic pain in pregnancy. Spine (Phila Pa 1976) 1994 Apr 15;19(8):894-900.

14. Ostgaard HC, Roos-Hansson E, Zetherstrom G. Regression of back and posterior pelvic pain after pregnancy. Spine (Phila Pa 1976) 1996 Dec 1;21(23):2777-2780.

15. Ostgaard HC, Zetherstrom G, Roos-Hansson E. The posterior pelvic pain provocation test in pregnant women. Eur Spine J 1994 Oct;3(5):258-260.

16. Haugland KS, Rasmussen S, Daltveit AK. Group intervention for women with pelvic girdle pain in pregnancy. A randomized controlled trial. Acta Obstet Gynecol Scand 2006 Nov;85(11):1320-1326.

17. Sturesson B, Uden G, Uden A. Pain pattern in pregnancy and "catching" of the leg in pregnant women with posterior pelvic pain. Spine (Phila Pa 1976) 1997 Aug;22(16):1880-1883; discussion 1884.

18. Johnson D, Coley S. Back pain in pregnancy. J R Soc Med 1998 Jun;91(6):344. 
19. Leboeuf-Yde C, van Dijk J, Franz C, Hustad SA, Olsen D, Pihl T, Röbech R, Skov Vendrup S, Bendix T, Kyvik KO. Motion palpation findings and self-reported low back pain in a population-based study sample. J Manipulative Physiol Ther 2002 Feb;25(2):80-87.

20. Fogarty V. Intradermal sterile water injections for the relief of low back pain in labour - a systematic review of the literature. Women Birth 2008 Dec;21(4):157-163.

21. Bailey A. Risk factors for low back pain in women: still more questions to be answered. Menopause 2009 Jan-Feb;16(1):3-4.

22. Wang SM, Dezinno P, Maranets I, Berman MR, CaldwellAndrews AA, Kain ZN. Low back pain during pregnancy: prevalence, risk factors, and outcomes. Obstet Gynecol 2004 Jul;104(1):65-70.

23. Mens JM, Vleeming A, Stoeckart R, Stam HJ, Snijders CJ. Understanding peripartum pelvic pain. Implications of a patient survey. Spine (Phila Pa 1976) 1996 Jun 1;21(11): 1363-1369; discussion 1369-1370.

24. Sandler SE. The management of low back pain in pregnancy. Man Ther 1996 Sep;1(4):178-185.

25. de Groot M, Pool-Goudzwaard AL, Spoor CW, Snijders CJ. The active straight leg raising test (ASLR) in pregnant women: differences in muscle activity and force between patients and healthy subjects. Man Ther 2008 Feb;13(1):68-74.

26. Vadivelu R, Green TP, Bhatt R. An uncommon cause of back pain in pregnancy. Postgrad Med J 2005 Jan;81(951):65-67.

27. van de Pol G, de Leeuw JR, van Brummen HJ, Bruinse HW, Heintz AP, van der Vaart $\mathrm{CH}$. The Pregnancy Mobility Index: a mobility scale during and after pregnancy. Acta Obstet Gynecol Scand 2006;85(7):786-791.

28. Leadbetter RE, Mawer D, Lindow SW. Symphysis pubis dysfunction: a review of the literature. J Matern Fetal Neonatal Med 2004 Dec;16(6):349-354.

29. Baxley EG, Gobbo RW. Shoulder dystocia. Am Fam Physician 2004 Apr;69(7):1707-1714.

30. Chalidis B, Fahel LA, Glanville T, Kanakaris N, Giannoudis PV. Management and reconstruction of pelvic instability after emergency symphysiotomy. Int J Gynaecol Obstet 2007 Sep;98(3):264-266.

31. Tile M. Management of pelvic ring injuries. In: Tile M, Helfet $D_{\text {, }}$ Kellam J, editors. Fractures of the pelvis and acetabulum. Lippincott Williams \& Wilkins; 2003. p. 168-216.

32. Mogren IM. Physical activity and persistent low back pain and pelvic pain post partum. BMC Public Health 2008 Dec 22;8:417.

33. Stapleton DB, MacLennan AH, Kristiansson P. The prevalence of recalled low back pain during and after pregnancy: a South Australian population survey. Aust N Z J Obstet Gynaecol 2002 Nov;42(5):482-485.

34. Mens JM, Damen L, Snijders CJ, Stam HJ. The mechanical effect of a pelvic belt in patients with pregnancy-related pelvic pain. Clin Biomech (Bristol, Avon) 2006 Feb;21(2):122-127.

35. Ostgaard HC, Andersson GB, Karlsson K. Prevalence of back pain in pregnancy. Spine (Phila Pa 1976) 1991 May;16(5):549-552.

36. Larsen EC, Wilken-Jensen C, Hansen A, Jensen DV, Johansen S, Minck H, Wormslev M, Davidsen M, Hansen TM. Symptomgiving pelvic girdle relaxation in pregnancy. I: Prevalence and risk factors. Acta Obstet Gynecol Scand 1999 Feb;78(2): 105-110.

37. Bjorklund $\mathrm{K}$, Bergstrom S. Is pelvic pain in pregnancy a welfare complaint? Acta Obstet Gynecol Scand 2000;79(1):24-30
38. Mogren IM, Pohjanen AI. Low back pain and pelvic pain during pregnancy: prevalence and risk factors. Spine (Phila Pa 1976) 2005 Apr 15;30(8):983-991.

39. Padua L, Padua R, Bondi R, Ceccarelli E, CaliandroP, D'Amico P, Mazza O, Tonali P. Patient-oriented assessment of back pain in pregnancy. Eur Spine J 2002 Jun;11(3):272-275.

40. MacLennan AH, MacLennan SC. Symptom-giving pelvic girdle relaxation of pregnancy, postnatal pelvic joint syndrome and developmental dysplasia of the hip. The Norwegian Association for Women with Pelvic Girdle Relaxation (Landforeningen for Kvinner Med Bekkenlosningsplager). Acta Obstet Gynecol Scand 1997 Sep;76(8):760-764.

41. Mogren IM. BMI, pain and hyper-mobility are determinants of long-term outcome for women with low back pain and pelvic pain during pregnancy. Eur Spine J 2006 Jul;15(7):1093-1102.

42. Mogren IM. Does caesarean section negatively influence the post-partum prognosis of low back pain and pelvic pain during pregnancy? Eur Spine J 2007 Jan;16(1):115-121.

43. Morkved S, Salvesen KA, Schei B, Lydersen S, Bo K. Does group training during pregnancy prevent lumbopelvic pain? A randomized clinical trial. Acta Obstet Gynecol Scand 2007;86(3):276-282.

44. Gutke A, Ostgaard HC, Oberg B. Association between muscle function and low back pain in relation to pregnancy. J Rehabil Med 2008 Apr;40(4):304-311.

45. Tzeng YL, Su TJ. Low back pain during labor and related factors. J Nurs Res 2008 Sep;16(3):231-241.

46. Gutke A, Ostgaard HC, Oberg B. Predicting persistent pregnancy- related low back pain. Spine (Phila Pa 1976) 2008 May 20;33(12):E386-E393.

47. Bastiaenen $\mathrm{CH}$, de Bie RA, Wolters PM, Vlaeyen JW, Leffers P, Stelma F, Bastiaanssen JM, Essed GG, van den Brandt PA. Effectiveness of a tailor-made intervention for pregnancy-related pelvic girdle and/or low back pain after delivery: short-term results of a randomized clinical trial [ISRCTN08477490]. BMC Musculoskelet Disord 2006 Feb 27;7:19.

48. Van De Pol G, Van Brummen HJ, Bruinse HW, Heintz AP, Van Der Vaart $\mathrm{CH}$. Pregnancy-related pelvic girdle pain in the Netherlands. Acta Obstet Gynecol Scand 2007;86(4):416-422.

49. Mens JM, Snijders CJ, Stam HJ. Diagonal trunk muscle exercises in peripartum pelvic pain: a randomized clinical trial. Phys Ther 2000 Dec;80(12):1164-1173.

50. Vollestad NK, Stuge B. Prognostic factors for recovery from postpartum pelvic girdle pain. Eur Spine J 2009 May;18(5):718-726.

51. Mogren IM. Previous physical activity decreases the risk of low back pain and pelvic pain during pregnancy. Scand J Public Health 2005;33(4):300-306.

52. Wang SM, Dezinno P, Lin EC, Lin H, Yue JJ, Berman MR, Braveman F, Kain ZN. Auricular acupuncture as a treatment for pregnant women who have low back and posterior pelvic pain: a pilot study. Am J Obstet Gynecol 2009 Sep;201(3):271. e1-271.e9.

53. Ostgaard HC, Zetherstrom G, Roos-Hansson E. Back pain in relation to pregnancy: a 6-year follow-up. Spine (Phila Pa 1976) 1997 Dec 15;22(24):2945-2950.

54. Bastiaenen CH, de Bie RA, Vlaeyen JW, Goossens ME, Leffers P, Wolters PM, Bastiaanssen JM, van den Brandt PA, Essed GG. Long-term effectiveness and costs of a brief self-management 
intervention in women with pregnancy-related low back pain after delivery. BMC Pregnancy Childbirth 2008 May 30;8:19.

55. Bastiaenen $\mathrm{CH}$, de Bie RA, Wolters PM, Vlaeyen JW, Bastiaanssen JM, Klabbers AB, Heuts A, van den Brandt PA, Essed GG. Treatment of pregnancy-related pelvic girdle and/or low back pain after delivery design of a randomized clinical trial within a comprehensive prognostic cohort study [ISRCTN08477490]. BMC Public Health 2004 Dec 24;4:67.
56. Noren L, Ostgaard S, Nielsen TF, Ostgaard HC. Reduction of sick leave for lumbar back and posterior pelvic pain in pregnancy. Spine (Phila Pa 1976) 1997 Sep;22(18):2157-2160.

57. Lund I, Lundeberg T, Lonnberg L, Svensson E. Decrease of pregnant women's pelvic pain after acupuncture: a randomized controlled single-blind study. Acta Obstet Gynecol Scand 2006 Jan;85(1):12-19.

58. Kvorning N, Holmberg C, Grennert L, Aberg A, Akeson J. Acupuncture relieves pelvic and low-back pain in late pregnancy. Acta Obstet Gynecol Scand 2004 Mar;83(3):246-250. 